\title{
Femoral Nerve Palsy following Medial Patella Femoral Ligament Reconstruction
}

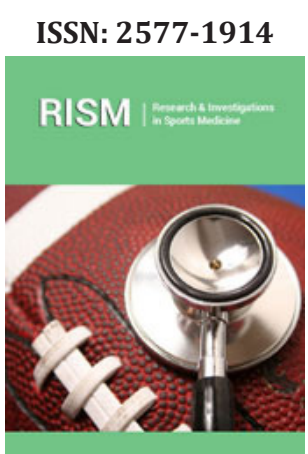

*Corresponding author: Laughter Lisenda, Division of Orthopaedics, Faculty of Health Sciences, University of the Witwatersrand, 7 York Road, Parktown, Johannesburg, South Africa

Submission: 侮 May 04, 2020

Published: 偪June 05, 2020

Volume 6 - Issue 4

How to cite this article: Lisenda L, Mokete L. Femoral Nerve Palsy following Medial Patella Femoral Ligament Reconstruction. Res Inves Sports Med, 6(4): RISM.000642. 2020. DOI: 10.31031/RISM.2020.06.000642

Copyright@ Lisenda L, This article is distributed under the terms of the Creative Commons Attribution 4.0 International License, which permits unrestricted use and redistribution provided that the original author and source are credited.

\section{Lisenda $\mathrm{L}^{1 *}$ and Mokete $\mathrm{L}^{2}$}

${ }^{1}$ Research Fellow, Division of Orthopaedics, University of the Witwatersrand, South Africa

${ }^{2}$ Consultant Orthopaedic Surgeon, Division of Orthopaedic Surgery, University of the Witwatersrand, South Africa

\section{Abstract}

Case: A 29-year-old teacher, presented with right medial patellofemoral ligament (MPFL) tear. This was identified and confirmed by magnetic imaging resonance and MPFL was reconstructed with gracilis tendon. She had femoral nerve palsy that recovered fully after prolonged rehabilitation.

Conclusion: Femoral nerve palsy secondary to pneumatic pressure is uncommon. Fortunately, most of the injured femoral nerves recover spontaneously without any neurological sequelae. There is controversy in the literature regarding the optimal pneumatic pressure for lower limb and duration of the tourniquet. We report a case of femoral nerve palsy secondary to pneumatic pressure.

Abbrevations: MPFL: Medial Patella Femoral Ligament; EMG: Electromyelography; TKA: Total Knee Arthroplasty; MRI: Magnetic Resonance Imaging

\section{Introduction}

Pneumatic tourniquets are used to provide bloodless surgical field and minimize blood loss [1,2]. Iatrogenic femoral nerve palsy as a result of tourniquet use is uncommon [3-5]. This may be underreported because of weakness of the quadriceps muscle from the surgical procedure and rapid recovery of the nerve [3]. Both ischemic and mechanical processes have been implicated in the pathophysiology of the femoral nerve palsy [2,6-9]. We report a case of femoral nerve palsy after medial patella femoral ligament (MPFL) reconstruction with gracilis tendon using a tourniquet.

\section{Case Report}

A 29 year-old teacher, presented with a history of recurrent instability of the right patella. The first episode occurred post fall during gym exercises and the patella shifted outwards. This was reduced by the gym instructor and she was subsequently put on a patella knee brace by the general practitioner. After removal of the brace she had multiple recurrent falls with the patella dislocating laterally and was unable to do exercises without a brace. Clinically there was effusion on the knee with positive grinding test. The 'J sign' was positive. X-rays showed laterally subluxed right patella as shown on the skyline view as shown in Figure 1. The TT -TG was $16 \mathrm{~mm}$ with no trochlear dysplasia and with Insall Salvati ratio of 0.75 with normal alignment of the right lower limb. MRI revealed complete tear of MPFL (Figure 2). We therefore proceeded to do isolated MPFL reconstruction with Gracilis tendon autograft under spinal anaesthesia and tourniquet was inflated to $300 \mathrm{mmHg}$ for 115 minutes (See Figure 3). The average Blood pressure was 118/68 intraoperatively. The operation was uneventfully.

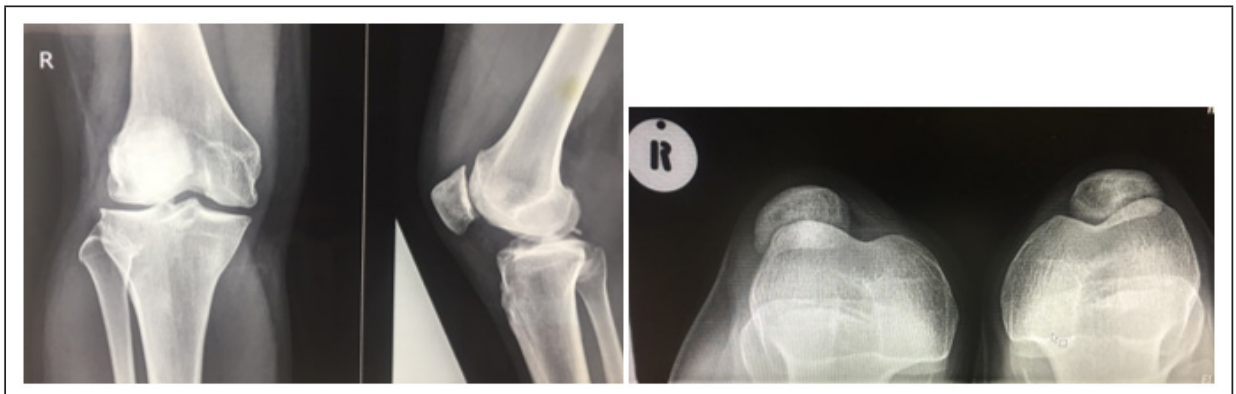

Figure 1: Pre-operative $\mathrm{x}$-rays (Shows lateral sublimed right patella). 

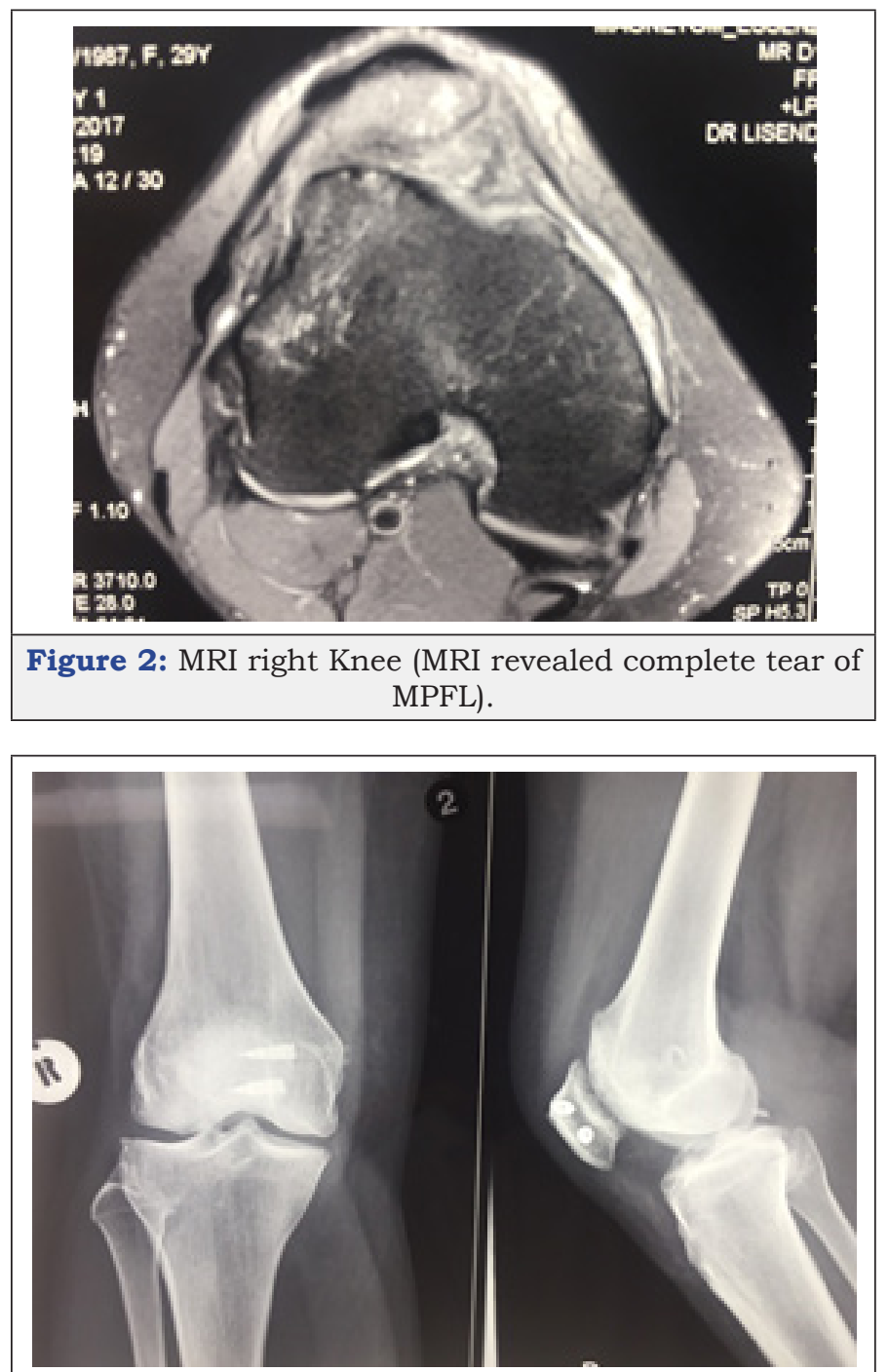

Figure 3: Immediate post-operative x-rays. Reduced patella.

On day 1 post-operative she was unable to extend the knee. For the first 6 weeks post-operative L2 nerve root power was 0/5 on a five-point scale, with significant wasting of quadriceps at 6 weeks. There was gradually improvement of power to $3 / 5$ at 3 months follow-up. Electromyelography (EMG) done at 4 months revealed chronic axonal femoral neuropathy on the right at the level of the tourniquet. The findings were consistent with both compressive and subsequent ischemia of the nerve. There was no electrophysiological evidence of a lumbosacral plexopathy/ radiculopathy. Side-to-side comparison of femoral motor response revealed an approximate $25 \%$ axonal loss on the right with no electrophysiological evidence of an on-going demyelinating lesion at the inguinal ligament. At 9 months post-operative the power was $4.5 / 5$. At 1 year follow-up the power was $5 / 5$ and comparable to the left side.

\section{Discussion}

Iatrogenic femoral nerve palsy is uncommon. There are few case reports in the literature documenting femoral nerve palsy relating to knee surgery $[6,10,11]$. The lower incidence is partly attributed to the weakness of quadriceps muscle from the surgical procedure and rapid recovery of femoral nerve [3]. Horlocker et al. [2] however reported the incidence of $7.7 \%$ in patients who underwent TKA [2].

In our case the femoral nerve palsy was secondary to inflating the tourniquet to high pressure of $300 \mathrm{mmHg}$ after excluding other causes. The tourniquet time was 115 minutes. Also, our patient was masculine with (BMI of 25.8, Body fat $22 \%$ and Muscle mass $52 \%$ ) hence decreasing the 'cushioning effect' of adipose around the femoral nerve. Mechanical compression and ischemia have been documented well in the literature as cause of nerve palsy. The longer the duration of tourniquet the more likely that one will get a neuropraxia [6,12] however intermittent deflation during procedure modestly decreased the risk of neuropraxia. Compression plays more important role after 2-3 hours. This effect is directly under the cuff and spreads distal [5]. Ischemia affects the muscle as well [5].

To prevent femoral nerve injury tourniquets must be applied to the proximal part of the limb at the greatest circumference because the muscle bulk at that site is the greatest, and hence it affords a greater protection against nerve injury. The tourniquets must be well padded and the inflation pressure must be $100-150 \mathrm{mmHg}$ above systolic pressure and or $300 \mathrm{mmHg}$ for not more than 2 hours.

\section{Conclusion}

Neurapraxia of the femoral nerve secondary to pneumatic tourniquet are uncommon. Currently there is no universal adopted safe tourniquet time and pressure. Therefore prevention of this complication by inflating pneumatic tourniquet to above 100$150 \mathrm{mmHg}$ of systolic high blood pressure and not more than $300 \mathrm{mmHg}$ for not more than 2 hours continuously should be adhered to at all times. Extra caution in patients with low body fat percentage and high muscle content must be taken by applying lower pneumatic pressures to avoid additive compression of the nerve by muscle.

\section{References}

1. Sharma JP, Salhotra R (2012) Tourniquets in orthopedic surgery. Indian J Orthop 46 (4): 377-383.

2. Horlocker TT, Hebl JR, Gali B, Jankowski CJ, Burkle CM, et al. (2006) Anesthetic, patient, and surgical risk factors for neurologic complications after prolonged total tourniquet time during total knee arthroplasty. Anesth Analg 102(3): 950-955.

3. Moore AE, Stringer MD (2011) Iatrogenic femoral nerve injury: a systematic review. Surg Radiol Anat 33(8): 649-658.

4. Dobner JJ, Nitz AJ (1982) Postmeniscectomy tourniquet palsy and functional sequelae. Am J Sports Med 10(4): 211-214.

5. Mingo-Robinet J, Castañeda-Cabrero C, Alvarez V, Alonso-Cortés JLM, Monge-Casares E (2013) Tourniquet-related iatrogenic femoral nerve palsy after knee surgery: case report and review of the literature. Case Rep Orthop 2013: 368290.

6. Saunders KC, Louis DL, Weingarden SI, Waylonis GW (1979) Effect of tourniquet time on postoperative quadriceps function. Clin Orthop Relat Res (143): 194-199. 
7. Mackinnon SE (2002) Pathophysiology of nerve compression. Hand Clin 18(2): 231-241.

8. Lundborg G, Myers R, Powell H (1983) Nerve compression injury and increased endoneurial fluid pressure: a "miniature compartment syndrome." J Neurol Neurosurg Psychiatry 46(12): 1119-1124.

9. Powell HC, Myers RR (1986) Pathology of experimental nerve compression. Lab Invest 55(1): 91-100.
10. Kornbluth ID, Freedman MK, Sher L, Frederick RW (2003) Femoral, saphenous nerve palsy after tourniquet use: a case report. Archives of Physical Medicine and Rehabilitation 84(6): 909-911.

11. Moore AE, Stringer MD (2011) Iatrogenic femoral nerve injury: a systematic review. Surgical and radiologic anatomy 33(8): 649-658.

12. Rorabeck CH (1980) Tourniquet-induced nerve ischemia: an experimental investigation. Journal of Trauma 20(4): 280-286. 